\title{
5 Los factores verbales desde una perspectiva diacrónica: estudio de corpus
}

\subsection{Introducción}

En el capítulo 4 se ha presentado un trabajo de investigación sincrónico acerca de la influencia de la afectación y la telicidad en el MDO. Los resultados de dicho trabajo han indicado que, por un lado, la afectación desempeña un papel importante en la explicación del fenómeno y, por otro lado, la telicidad también parece ejercer algún tipo de influencia en el MDO, aunque la naturaleza de dicho impacto no parece estar tan clara como en el caso de la afectación.

El objetivo de este capítulo es triple. En principio, se pretende investigar si los efectos que han arrojado los resultados de la investigación sincrónica pueden documentarse también en etapas previas de la evolución del MDO. Asimismo, la finalidad de un trabajo diacrónico es comprobar en qué medida los datos de épocas anteriores pueden contribuir no solo a indicar si la telicidad y la afectación ya eran relevantes anteriormente, sino también a comprender cuál es la naturaleza de los resultados que se han obtenido para la sincronía. Por último, podría decirse que este capítulo viene a complementar los escasos estudios previos acerca del impacto diacrónico de la afectación en el MDO y remediar la ausencia total de datos en lo referido a la influencia diacrónica de la telicidad en los objetos directos con referente humano.

La investigación diacrónica ha consistido en la realización de un análisis que comprende los siglos XIV, XVI y Xx, basado en el Corpus del Nuevo Diccionario Histórico del Español (CDH) ${ }^{23}$. Los resultados de este trabajo han arrojado una imagen sumamente coherente con respecto a la obtenida en el capítulo anterior, pues mientras que la afectación consolida su posición como factor determinante del MDO, la telicidad parece diluir aún más ese efecto que se obtenía en los cuestionarios y cuya naturaleza no acababa de estar del todo clara.

Este capítulo continúa con el planteamiento de la hipótesis que motiva el análisis diacrónico (apartado 5.2) y, posteriormente, con la descripción de cuál ha sido la metodología utilizada (apartado 5.3). El siguiente apartado, el 5.4, recoge los resultados obtenidos del análisis en diferentes subapartados, atendiendo a los distintos factores que han sido tenidos en cuenta. A continuación, dichos resultados son comentados con mayor detenimiento y analizados en el apartado

23 Romero Heredero (2021), asimismo, presenta y analiza en profundidad los resultados derivados de este estudio respecto al factor de la telicidad. 
5.5 y, por último, el apartado 5.6 recoge las ideas y conclusiones más relevantes alcanzadas tras la realización del estudio.

\subsection{Hipótesis}

El estudio que se presenta a continuación se sustenta en unas hipótesis paralelas a las propuestas para el análisis sincrónico, pero referidas a las etapas previas del MDO. Dichas hipótesis se asientan asimismo en los conceptos de telicidad y afectación establecidos en el capítulo anterior. La telicidad se considera una propiedad del SV, constituida por el valor aspectual del verbo y los posibles constituyentes internos al SV que pueden, bien medir el evento, o bien delimitarlo. En lo que respecta a la afectación, se consideran afectados todos aquellos participantes en el evento que son receptores de una fuerza (definición que excluye al Agente en cualquiera de los casos, por ser él el iniciador del evento y, por lo tanto, quien transmite la fuerza).

Consecuentemente, las pruebas gramaticales que se han aplicado a cada uno de los ejemplos extraídos del corpus para clasificarlos han sido las mismas que las utilizadas en el capítulo anterior (presentadas de nuevo en (94) y (95)). Así pues, se considera que un predicado es télico (94a) cuando admite un SP que, encabezado por la preposición en, delimita el evento y que es atélico, cuando la adición de dicho sintagma provoca la anomalía de la estructura. Por otro lado, un objeto directo se clasifica como afectado cuando el SN que lo constituye es capaz de aparecer en los contextos de (95) y no provocar una anomalía en la estructura resultante; de esta manera, el coche en (95a) se considera un objeto afectado, mientras que este no es el caso de sus vecinos en (95b).

(94) Prueba de telicidad (Vendler 1957, 145-146)

a. María corre un kilómetro en cinco minutos.

b. \#María corre en cinco minutos.

(95) Prueba de afectación (Jackendoff 1990, 125)

$$
\left\{\begin{array}{c}
\text { Lo que le ocurrió } \\
\text { Lo que x le hizo }
\end{array}\right\} \text { a SN fue... }
$$

a. Luis destrozó el coche.

Lo que le ocurrió a al coche fue que Luis lo destrozó.

Lo que Luis le hizo al coche fue destrozarlo.

b. María conoce a sus vecinos.

\#Lo que les ocurre a sus vecinos es que María los conoce.

\#Lo que María les hizo a sus vecinos fue conocerlos. 
Al igual que en el capítulo previo, una vez establecidos los conceptos básicos en los que se sustenta la investigación, se puede proceder a la formulación de las hipótesis. En este caso, dichas hipótesis aparecen plasmadas en (96) y están basadas en los trabajos diacrónicos presentados en el capítulo 3 que defienden que tanto la afectación (von Heusinger/Kaiser 2011) como la telicidad (Barraza Carbajal 2003a; 2008) ejercen su influencia sobre el MDO en español.

(96) Hipótesis

H1: Los objetos directos de predicados télicos presentan con mayor frecuencia MDO que los objetos directos de predicados atélicos.

H2: Los objetos directos afectados por la acción del verbo presentan con mayor frecuencia MDO que los objetos no afectados.

La diferencia respecto al capítulo 4, como ya se ha comentado, es que las dos mismas hipótesis se aplican ahora a la evolución del MDO y no a su situación actual.

\subsection{Diseño del estudio}

El presente estudio está basado en el Corpus del Diccionario Histórico de la lengua española (CDH). Dicho corpus pertenece a la Real Academia Española (RAE) y ha sido creado por el Instituto de Investigación Rafael Lapesa. Consta de más de 400 millones de registros que se distribuyen en tres capas de consulta: (i) el Corpus nuclear del $C D H$, (ii) un conjunto de textos enmarcados entre el siglo XII y 1975 procedentes del Corpus Diacrónico del Español (CORDE) y (iii) una selección de obras datadas entre 1975 y 2000 procedentes del Corpus de Referencia del Español Actual (CREA). Los textos que integran el corpus proceden, no solo de España, sino también de los distintos países hispanohablantes del continente americano. En lo referente al manejo de los datos, se trata de un corpus en línea, al que se puede acceder a través de la página de la RAE o de la propia web del Instituto Rafael Lapesa. La aplicación permite realizar búsquedas partiendo de lemas, formas concretas o categorías gramaticales. Asimismo, los resultados se pueden filtrar atendiendo, tanto a criterios textuales (título, autor, origen, fecha de creación o tema), como a criterios de proximidad, es decir, al tipo de elementos que rodean al lema o forma que constituye el objeto de búsqueda. Desafortunadamente, el CDH no permite la búsqueda de patrones sintácticos determinados del tipo del MDO.

La búsqueda realizada se ha restringido a los siglos XIV, XVI y xx y al conjunto de variedades que conforman el «español de España». La cantidad de datos 
de fuentes españolas que contiene el corpus es más que suficiente para llevar a cabo un estudio diacrónico de estos tres períodos, ya que alberga más de siete millones y medio de palabras para el siglo xIV, casi cincuenta millones para el siglo XVI y más de ciento trece millones para el siglo xx. La selección de los tres períodos incluidos en el estudio ha tenido en cuenta el estudio de Octavio de Toledo y Huerta (2005) y ha evitado la etapa a la que este se refiere como primer español moderno, que abarcaría desde mediados del siglo XVII a comienzos del siglo xIx (véase Kabatek 2016, para un análisis más detallado). El período comprendido entre el español de los Siglos de Oro y nuestros días se ha considerado tradicionalmente una etapa de escaso interés lingüístico, en cuanto al estudio del cambio lingüístico se refiere. Se consideraba que, desde la creación de la RAE a comienzos del siglo XVIII, se había consolidado lo que hoy en día conocemos como español moderno y los cambios habían sido mínimos desde entonces. Este escaso interés ha repercutido en la representación textual que se puede encontrar de este período en el CORDE y, por lo tanto, en el CDH, cuyas frecuencias absolutas de registros son muy inferiores para este período a las del resto de etapas representadas en el corpus. Además, Octavio de Toledo y Huerta (2005, 421-422) apunta que, lejos de tratarse de una época de estabilidad lingüística, constituye una etapa de gran variación que no alcanzó estabilidad hasta comienzos del siglo XIX. Por lo tanto, teniendo en cuenta la infrarrepresentación en el corpus y los elevados niveles de variación que apunta Octavio de Toledo, se ha optado por evitar dicho período y escoger tres etapas que estuviesen bien diferenciadas entre sí y que, al mismo tiempo, presentasen suficiente estabilidad interna que, sumada a una amplia representación en el corpus, facilitase la tarea de llevar a cabo el presente estudio diacrónico.

Los resultados del análisis están basados en 3200 casos de SN léxicos con función de objeto directo, definidos e indefinidos, con referente humano, todos ellos localizados en posición posverbal (SVO). Quedan excluidos, por tanto, los SN con referente animado no humano o inanimado, los nombres propios, los SN sin determinante y los SN dislocados a la izquierda. Una vez controlados estos factores, se procedió a la búsqueda y extracción de los casos del corpus atendiendo a una distribución predeterminada. Dicha distribución no es aleatoria, sino que responde a la intención de comparar distintos conjuntos definidos cada uno por una serie de rasgos, con independencia de la frecuencia con que dichos rasgos aparecen en el corpus. Para ello, se ha diseñado un reparto del total de casos vertebrado por los principales factores que la bibliografía previa ha señalado como relevantes en la evolución del MDO en español (véase Tabla 5.1). Como se puede observar, más allá de la animacidad, el tipo de expresión referencial y la posición del objeto, que, como ya se ha dicho, se han fijado de manera previa a la extracción de los casos, la distribución responde fundamentalmente a los factores de telicidad y 
afectación, para los cuales se ha conseguido reunir un número equilibrado de casos, que se estructura atendiendo a al cruce de ambos factores, de manera que se puedan observar tanto sus efectos independientes, como su posible interacción. Además, como es lógico en un estudio de esta naturaleza, se ha tenido en cuenta el siglo. La cantidad de ejemplos recogidos para cada uno de los intervalos temporales estudiados guarda relación con el número de registros disponibles que contiene el corpus para cada uno de los siglos. Por último, en lo que respecta a la definitud, factor fundamental para explicar la evolución del MDO, la distribución de los ejemplos se justifica por la disponibilidad de SN definidos e indefinidos con función de objeto directo que se ha encontrado en el corpus.

Tabla 5.1: Distribución de los casos de estudio en frecuencias absolutas.

\begin{tabular}{llrrrr}
\hline & & XIV & XVI & XX & TOTALES \\
\hline [+afectado, +télico] & SN definido & 120 & 180 & 300 & 600 \\
\cline { 2 - 6 } & SN indefinido & 40 & 60 & 100 & 200 \\
\hline [+afectado, -télico] & SN definido & 120 & 180 & 300 & 600 \\
\cline { 2 - 6 } & SN indefinido & 40 & 60 & 100 & 200 \\
\hline [-afectado, -télico] & SN definido & 120 & 180 & 300 & 600 \\
\cline { 2 - 6 } & SN indefinido & 40 & 60 & 100 & 200 \\
\hline [-afectado, +télico] & SN definido & 120 & 180 & 300 & 600 \\
\cline { 2 - 6 } & SN indefinido & 40 & 60 & 100 & 200 \\
\hline & TOTALES & 640 & 960 & 1600 & 3200 \\
\hline
\end{tabular}

La selección de los casos que se han incorporado al estudio ha estado determinada por un proceso que garantizase la validez de estos dentro de cada uno de los conjuntos establecidos. Puesto que el CDH no permite la búsqueda de patrones sintácticos, ha sido necesario partir de elementos léxicos cuya búsqueda arrojase el mayor número posible de ejemplos válidos para el estudio, y, en este caso, dichos elementos léxicos han sido los verbos. La afectación que implica un determinado verbo generalmente no es dependiente del contexto en el que este aparece; por ello, se elegía un verbo cuyo objeto directo quedase o no afectado, dependiendo de las necesidades de la búsqueda. En lo que a la telicidad respecta, tal como se desprende de su definición, es un rasgo que se construye composicionalmente, por lo tanto, elegir un verbo inherentemente (a)télico no asegura que todos los casos que devuelva la búsqueda lo vayan a ser también; no obstante, como el corpus no ofrece otra posibilidad más sencilla, se partía de la telicidad inherente del verbo y se seleccionaba uno inherentemente (a)télico, dependiendo de los ejemplos que fuesen necesarios. Elegido el verbo, se lanzaba la búsqueda y 
se extraían todos los ejemplos posibles que respondiesen a los factores predeterminados. Una vez terminaba el proceso de búsqueda con un determinado verbo, se volvía a comenzar con la selección de otro y así sucesivamente hasta conseguir el número de casos suficiente para completar las cantidades previstas en la Tabla 5.1 (véase Anexo 2 para una descripción detallada del proceso de extracción de ejemplos). Cabe añadir que cuando se localizaba un caso en el corpus que cumpliese con los requisitos establecidos, antes de incorporarlo al conjunto destinado al análisis, se le aplicaban las dos pruebas correspondientes tal como puede apreciarse en (97).

(97) Incorporación de ejemplos al estudio

a. Mas aquel traidor que matara la donzella, tomó ende Dios tal vengança quele tornó el rostro más vermejo que brasa.

(1300-1325, Anónimo, Cuento muy fermoso de Otas de Roma).

Prueba de telicidad: $\quad$ Mas aquel traidor que matara la donzella (en pocos segundos)...

Prueba de afectación: Lo que le ocurrió a la donzella fue que aquel traidor la mató.

Lo que aquel traidor le hizo a la donzella fue matarla.

$\Rightarrow$ ejemplo clasificado como [+télico, +afectado]

b. Y el hombre [...] arrastró al artista al comedor, como del cuello, ansiando la venganza burda de aniquilarle en vino su histriónico descaro. (1914, Trigo, Los abismos)

Prueba de telicidad: $\quad$ M: Y el hombre arrastró al artista al comedor (en pocos segundos)...

Prueba de afectación: Lo que le ocurrió al artista fue que el hombre lo arrastró al comedor.

Lo que el hombre le hizo al artista fue arrastrarlo al comedor.

$\Rightarrow$ ejemplo clasificado como [+télico, +afectado]

El primero de los casos anteriores, el de (97a), se obtuvo en la búsqueda del verbo matar, clasificado en principio como [+télico, + afectado], y el caso concreto que se presenta fue finalmente clasificado atendiendo a esa misma descripción tras aplicar las pruebas. Sin embargo, el ejemplo presentado en (97b) se obtuvo en la búsqueda del verbo arrastrar, clasificado en primera instancia como [-télico, +afectado]; pero, tras aplicar las pruebas, fue clasificado en el grupo de ejemplos con los rasgos [+télico, +afectado], debido a que el adjunto al comedor establece en este caso un límite explícito que convierte en télico al evento. 
A posteriori, todos los casos extraídos del corpus han sido descritos también teniendo en cuenta el año, el autor, la obra, el verbo, la clase aspectual (estado/ actividad/realización/logro), el aspecto gramatical (perfectivo/imperfectivo) y, por supuesto, el MDO (presencia/ausencia). Respecto a los verbos que intervienen en el estudio, es importante señalar que se han establecido unos límites de representatividad dentro de cada uno de los conjuntos. Así pues, la representación de un único verbo puede alcanzar como máximo el 10\% del total de casos de un conjunto, asegurando de esta forma un mínimo de diez verbos en la constitución de cada uno de los conjuntos. Con esta medida se evita que los resultados correspondientes a cada uno de los conjuntos puedan responder al comportamiento de los verbos con mayor representación dentro del corpus.

\subsection{Resultados}

Este apartado recoge los resultados obtenidos tras el análisis de los casos que se han descrito en la sección previa. El tratamiento de los datos se ha llevado a cabo utilizando Microsoft Excel, programa en el que se han elaborado todas las figuras que se recogen en este capítulo. En lo que respecta al análisis estadístico, se han utilizado R (Team 2019) y lme4 (Bates et al. 2015) para desarrollar un modelo de regresión logística de efectos mixtos (glmer) de la relación entre el MDO y cada uno de los factores que se han tenido en cuenta en el estudio (definitud, telicidad, afectación, clase aspectual y aspecto gramatical), utilizando como efectos fijos dichos factores $y$, como efecto aleatorio, interceptos aleatorios ${ }^{24}$ para los distintos textos de los que proceden los ejemplos.

Los resultados aparecen representados en cinco subapartados diferentes atendiendo al factor analizado: el subapartado 5.4.1 presenta los resultados relativos a la definitud; el 5.4.2, los relativos a la telicidad; el subapartado 5.4.3, los que hacen referencia a la afectación; el 5.4.4 ofrece una visión de la interacción entre la telicidad y la afectación; y, por último, el subapartado 5.4.5 contiene los resultados referentes al resto de factores que han sido descritos de forma posterior a la extracción de casos del corpus, es decir, la clase aspectual y el aspecto gramatical.

24 Intercepto: Mat. (en un sistema de coordenadas) la distancia desde el origen hasta el punto en el cual una curva o una recta intersecciona con el eje. La función de establecer el intercepto como efecto aleatorio para los textos de origen, en este caso, es la de descartar los efectos que pudieran surgir derivados de las características no controladas que definen cada texto como el autor, el tema o la tipología textual, por ejemplo. 


\subsubsection{Definitud}

La definitud del objeto, aunque no es uno de los principales objetos de investigación en este trabajo, constituye uno de los factores sin los cuales es imposible entender la evolución del MDO en español, como han demostrado anteriormente algunos autores (Company Company 2002a; Laca 2006; entre otros). Por ello, antes de presentar los resultados relativos a la telicidad y la afectación, es importante incluir una visión general de los resultados relativos a la definitud del objeto obtenidos en el análisis, pues de aquí en adelante, para analizar el efecto del resto de factores, los resultados de los SN definidos y los de los indefinidos se presentan de forma independiente.

Los resultados representados en el Gráfico 5.1 muestran la frecuencia relativa de uso del MDO con relación al siglo (XIV/XVI/Xx) y a la definitud (SN definido/ $\mathrm{SN}$ indefinido). Las cantidades absolutas correspondientes aparecen recogidas en la Tabla 5.2. Así pues, los SN definidos en el siglo XIV presentan MDO en el $50 \%$ de los casos, frente al 28\% de los SN indefinidos. En lo que respecta al siglo XVI, el 65\% de los SN definidos con función de objeto directo presenta la marca preposicional, mientras que tan solo el 35\% de los SN indefinidos la muestra. Por último, en el siglo xx la frecuencia relativa de aparición de DOM con SN definidos es del 93\%, frente al 70\% de los SN indefinidos.

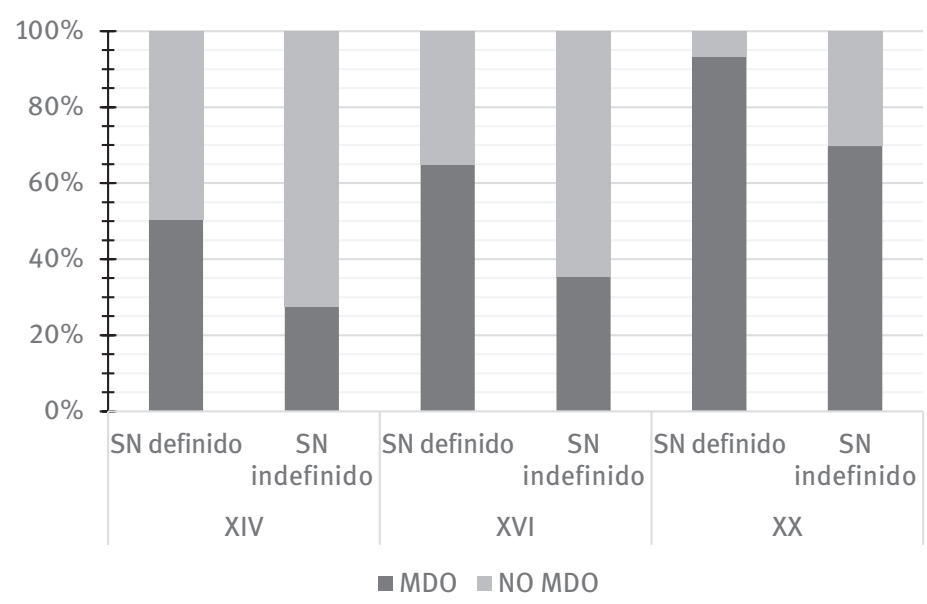

Gráfico 5.1: Frecuencia del MDO con respecto al siglo y la definitud.

Los datos obtenidos muestran un aumento de la frecuencia de objetos directos con MDO con relación al paso del tiempo; en otras palabras, el factor temporal (siglo) provoca un efecto significativo en el uso del MDO (estimado = 2,6; 
Tabla 5.2: Frecuencia del MDO con respecto al siglo y la definitud.

\begin{tabular}{llrrrr}
\hline & & \multicolumn{2}{c}{ MDO } & \multicolumn{2}{c}{ NO MDO } \\
\hline XIV & SN definido & $50 \%$ & $(242 / 480)$ & $50 \%$ & $(238 / 480)$ \\
\cline { 2 - 6 } & SN indefinido & $28 \%$ & $(44 / 160)$ & $73 \%$ & $(116 / 160)$ \\
\hline \multirow{2}{*}{ XVI } & SN definido & $65 \%$ & $(468 / 720)$ & $35 \%$ & $(252 / 720)$ \\
\cline { 2 - 6 } & SN indefinido & $35 \%$ & $(85 / 240)$ & $65 \%$ & $(155 / 240)$ \\
\hline XX & SN definido & $93 \%$ & $(1120 / 1200)$ & $7 \%$ & $(80 / 1200)$ \\
\cline { 2 - 6 } & SN indefinido & $70 \%$ & $(279 / 400)$ & $30 \%$ & $(121 / 400)$ \\
\hline
\end{tabular}

$\mathrm{p}<$ 0,001). Asimismo, es posible observar cómo los SN definidos favorecen la marca de acusativo frente a los SN indefinidos en cada uno de los períodos estudiados; de hecho, el análisis estadístico de los datos confirma la significatividad del efecto que tiene la definitud sobre la aparición del MDO (estimado = -1,22; $\mathrm{p}<0,001)$.

Estos resultados demuestran, tal como han señalado otros estudios previos al respecto, que el MDO se extendió antes a través de los objetos directos definidos que a través de los indefinidos. Sin embargo, las frecuencias de marcado preposicional en los SN indefinidos han sido sustancialmente superiores en este estudio (en torno a unos 30 puntos porcentuales en cada siglo) a las obtenidas por Laca (2006) en su análisis de corpus. Esto puede ser debido a la extensión de ambos análisis, pues de los aproximadamente 1600 casos de objetos directos contemplados por Laca, se ha pasado a los 3200 del presente estudio. Este hecho, sumado a que los casos de Laca se distribuyen entre 16 tipos de expresiones referenciales diferentes y los de este estudio abarcan únicamente dos, ha podido ser la causa de que los valores obtenidos en los SN indefinidos hayan sido superiores. Aun así, como ya hemos mencionado, la evolución del MDO que se aprecia con el paso del tiempo es totalmente paralela en ambos estudios.

En (98) se muestran ejemplos de objetos definidos e indefinidos del verbo ver para cada uno de los períodos estudiados. En el caso de los SN definidos, los tres ejemplos muestran MDO, mientras que los indefinidos, todos ellos aparecen sin marcado, en este caso.

(98) Objetos directos del verbo ver de los siglos XIV, XVI y XX

a) Vieron asy a su señor muerto (1300-1344, Anónimo, Crónica del moro Rasis)

b) Vido un cavallero mancebo que lo fazía mejor que quantos allí eran. (1300-1305, Anónimo, Libro del cavallero Cifar) 
c) Como Ypólito entró en el patio, vio a las damas que estavan por las ventanas.

(1511, Anónimo, Traducción de Tirante el Blanco de Joanot Martorell)

d) Vio vn moço que podia auer ocho años. (1500, Anónimo, Macer herbolario)

e) Vi a los insensatos de la Princesa, mandados por un paisano. (1900, Pérez Galdós, Los Ayachuchos)

f) No me causó pena ver un sacerdote en compañía de mi presunta esposa. (1900, Pérez Galdós, Los Ayachuchos)

\subsubsection{Telicidad}

En lo que a la telicidad se refiere, los resultados obtenidos son los que se pueden observar en los Gráficos 5.2 y 5.3 para los SN definidos e indefinidos, respectivamente. Asimismo, los datos absolutos correspondientes aparecen recogidos en las Tablas 5.3 y 5.4. En el caso de los objetos directos definidos, la frecuencia de uso del MDO en el siglo XIV es del 54\% en los predicados atélicos y del 47\% en los predicados télicos. En el siglo XVI los predicados atélicos muestran una frecuencia de uso de la marca preposicional del 66\%, mientras que los predicados télicos presentan la marca preposicional en el 64\% de los casos. Y en lo que al siglo Xx respecta, las frecuencias relativas son del 95\% y del 92\% para los predicados atélicos y los télicos, respectivamente.

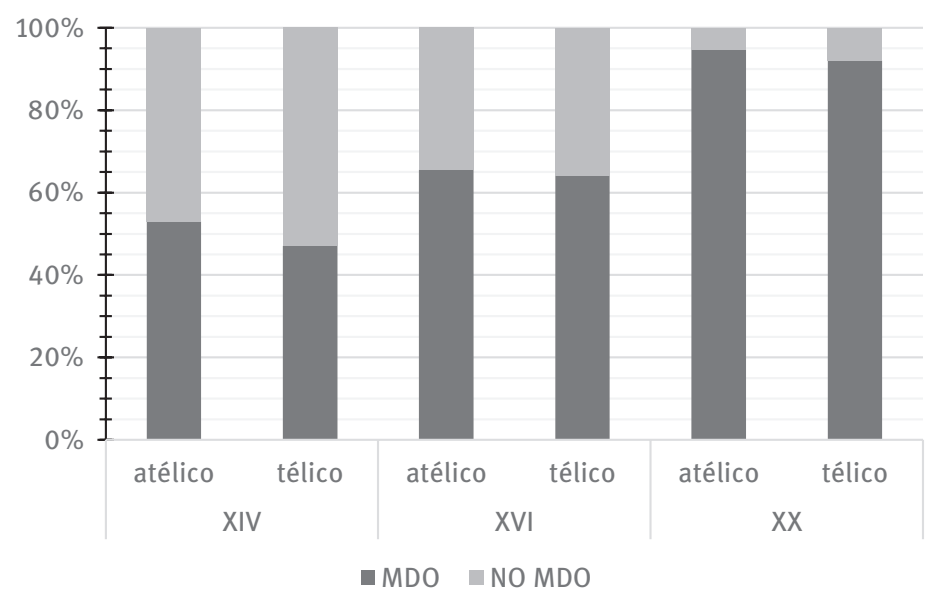

Gráfico 5.2: Frecuencia del MDO en SN definidos con respecto al siglo y la telicidad. 
Tabla 5.3: Frecuencia del MDO en SN definidos con respecto al siglo y la telicidad.

\begin{tabular}{lllllr}
\hline & & \multicolumn{2}{c}{ MDO } & \multicolumn{2}{c}{ NO MDO } \\
\hline XIV & atélico & $54 \%$ & $(129 / 240)$ & $46 \%$ & $(111 / 240)$ \\
\cline { 2 - 6 } & télico & $47 \%$ & $(113 / 240)$ & $53 \%$ & $(127 / 240)$ \\
\hline XVI & atélico & $66 \%$ & $(237 / 360)$ & $34 \%$ & $(123 / 360)$ \\
\cline { 2 - 6 } & télico & $64 \%$ & $(231 / 360)$ & $36 \%$ & $(129 / 360)$ \\
\hline \multirow{2}{*}{ XX } & atélico & $95 \%$ & $(568 / 600)$ & $5 \%$ & $(32 / 600)$ \\
\cline { 2 - 6 } & télico & $92 \%$ & $(552 / 600)$ & $8 \%$ & $(48 / 600)$ \\
\hline
\end{tabular}

Los ejemplos de (99) recogen un par de casos de objetos directos definidos pertenecientes al siglo XVI ambos con MDO, independientemente de la telicidad de sus predicados.

(99) SN definidos del siglo XVI con MDO

a) Tristán derribó al cavallero en tierra. (1501, Anónimo, Tristán de Leonís)

b) Los cavalleros conoscían a la princessa.

(1555, Ortúñez de Calahorra, Espejo de príncipes y caballeros)

En cuanto a los SN indefinidos, la frecuencia de uso del MDO queda distribuida de la siguiente manera: el 35\% de los objetos directos de predicados atélicos en el siglo XIV presenta la marca preposicional, frente al 20\% de los casos en predicados télicos; en el siglo XVI, la frecuencia de aparición del MDO en predicados atélicos es del 41\%, mientras que en predicados télicos es del 30\%; y, finalmente, en el siglo Xx, las frecuencias de uso del MDO son del 69\% y el 71\%, para los predicados atélicos y los predicados télicos, de forma respectiva.

En (100) se observan dos casos de objetos directos indefinidos que no reciben el marcado preposicional, independientemente del valor aspectual de sus respectivos predicados.

(100) SN indefinidos del siglo XVI sin MDO

a) Ellos encontraron un cavallero que traía una dueña. (1501, Anónimo, Tristán de Leonís)

b) A grandes voces oyeron un caballero llorar. (1508, Montesino, Cancionero) 


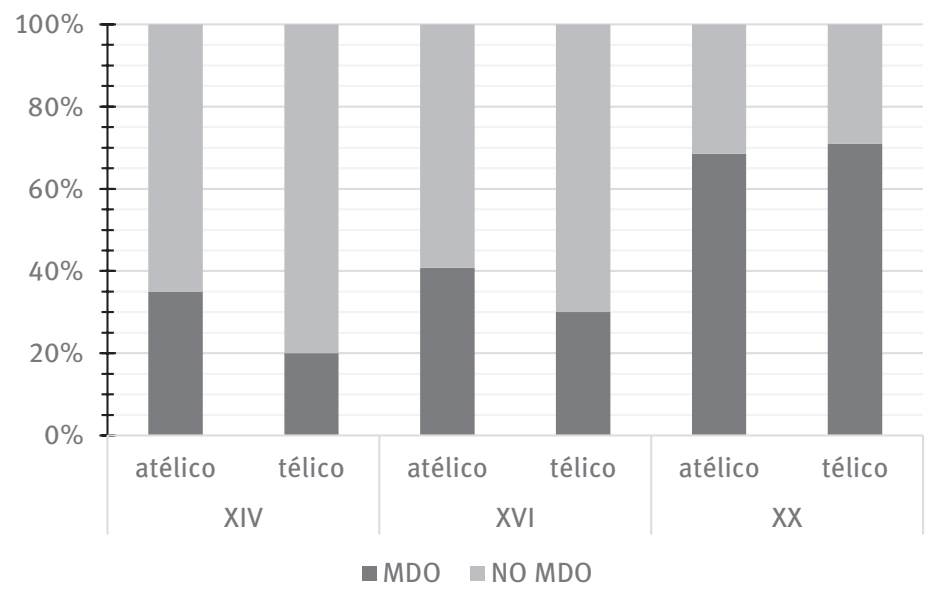

Gráfico 5.3: Frecuencia del MDO en SN indefinidos con respecto al siglo y la telicidad.

Tabla 5.4: Frecuencia del MDO en SN indefinidos con respecto al siglo y la telicidad.

\begin{tabular}{llrrrr}
\hline & & \multicolumn{2}{c}{ MDO } & \multicolumn{2}{c}{ NO MDO } \\
\hline XIV & atélico & $35 \%$ & $(28 / 80)$ & $65 \%$ & $(52 / 80)$ \\
\cline { 2 - 6 } & télico & $20 \%$ & $(16 / 80)$ & $80 \%$ & $(64 / 80)$ \\
\hline XVI & atélico & $41 \%$ & $(49 / 120)$ & $59 \%$ & $(71 / 120)$ \\
\cline { 2 - 6 } & télico & $30 \%$ & $(36 / 120)$ & $70 \%$ & $(84 / 120)$ \\
\hline \multirow{X}{*}{ a } & atélico & $69 \%$ & $(137 / 200)$ & $31 \%$ & $(63 / 200)$ \\
\cline { 2 - 6 } & télico & $71 \%$ & $(142 / 200)$ & $29 \%$ & $(58 / 200)$ \\
\hline
\end{tabular}

Por lo tanto, atendiendo a los resultados tanto de los objetos directos definidos como de los indefinidos se alcanza la conclusión de que el efecto de la telicidad sobre el MDO es, y ha sido en etapas anteriores, mínimo o inexistente. Se puede señalar, sin embargo, que los objetos indefinidos presentan una leve tendencia en los siglos XIV y XVI que parece apuntar a que los predicados atélicos favorecen ligeramente la aparición del MDO por encima de los télicos; a pesar de ello, el análisis estadístico de los datos sugiere que no supone un efecto significativo (estimado: $-0,67 ; \mathrm{p}=0,11$ ).

\subsubsection{Afectación}

Los Gráficos 5.4 y 5.5 presentan a continuación los resultados referentes al grado de afectación del objeto directo. El primero de ellos representa los casos de 
objetos directos definidos, mientras que el segundo, los de objetos directos indefinidos. Cada uno aparece acompañado de su respectiva tabla de valores absolutos (Tablas 5.5 y 5.6 para definidos e indefinidos, respectivamente). Así pues, en el siglo XIV los objetos afectados definidos muestran una frecuencia relativa de uso de MDO del 49\% y los objetos no afectados, del 52\%. En cuanto al siglo XVI, el $64 \%$ de los objetos afectados definidos presenta la marca preposicional, frente al $66 \%$ de los no afectados. Y, por último, en el siglo xx la frecuencia relativa de uso de MDO es del 95\% en los objetos afectados definidos y del 92\% en el caso de los no afectados.

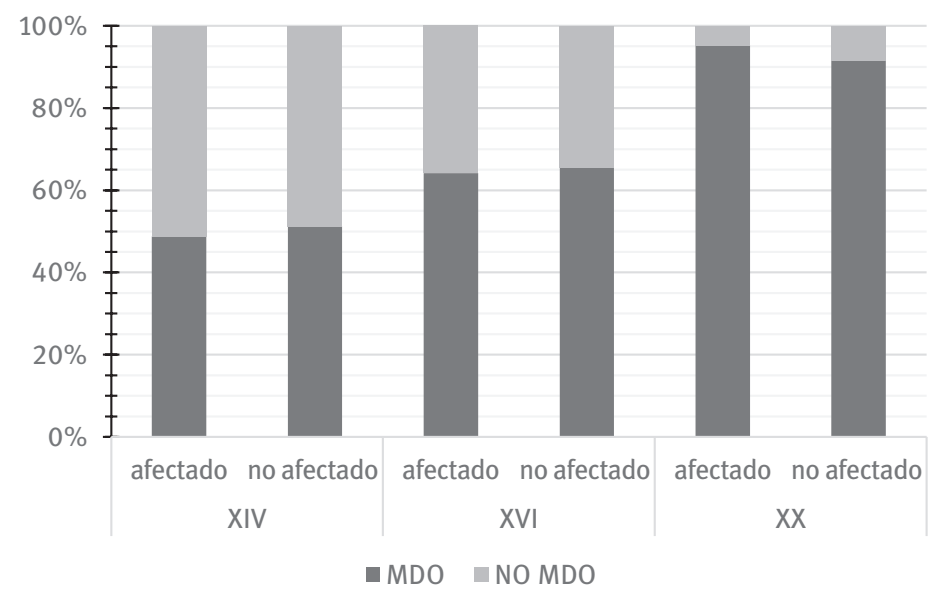

Gráfico 5.4: Frecuencia del MDO en SN definidos con respecto al siglo y la afectación.

Tabla 5.5: Frecuencia del MDO en SN definidos con respecto al siglo y la afectación.

\begin{tabular}{llllrr}
\hline & & \multicolumn{2}{c}{ MDO } & \multicolumn{2}{c}{ NO MDO } \\
\hline \multirow{2}{*}{ IIV } & afectado & $49 \%$ & $(117 / 240)$ & $51 \%$ & $(123 / 240)$ \\
\cline { 2 - 6 } & no afectado & $52 \%$ & $(125 / 240)$ & $48 \%$ & $(115 / 240)$ \\
\hline XVI & afectado & $64 \%$ & $(232 / 360)$ & $36 \%$ & $(128 / 360)$ \\
\cline { 2 - 6 } & no afectado & $66 \%$ & $(236 / 360)$ & $34 \%$ & $(124 / 360)$ \\
\hline XX & afectado & $95 \%$ & $(571 / 600)$ & $5 \%$ & $(29 / 600)$ \\
\cline { 2 - 6 } & no afectado & $92 \%$ & $(549 / 600)$ & $8 \%$ & $(51 / 600)$ \\
\hline
\end{tabular}

Los casos recogidos en (101) corresponden a dos objetos directos definidos del siglo xx que presentan MDO, independientemente de su respectivo grado de afectación. 
(101) SN definidos del siglo xx con MDO

a) Apalean a sus compañeros.

(1945, Sarabia, ¿Cómo se educan los hijos?)

b) Yo conocía también a su mujer. (1903, Azorín, Antonio Azorín)

En lo que a los SN indefinidos respecta, en el siglo XIv los objetos afectados muestran una frecuencia relativa del 39\%, mientras que en los no afectados es solo del $16 \%$. En el siglo XVI, las frecuencias de uso del MDO son del $45 \%$ y del $26 \%$, para los objetos afectados y los no afectados, respectivamente. $Y$ en el siglo xx el $84 \%$ de los objetos afectados poseen la marca preposicional, frente al $56 \%$ de los objetos no afectados.

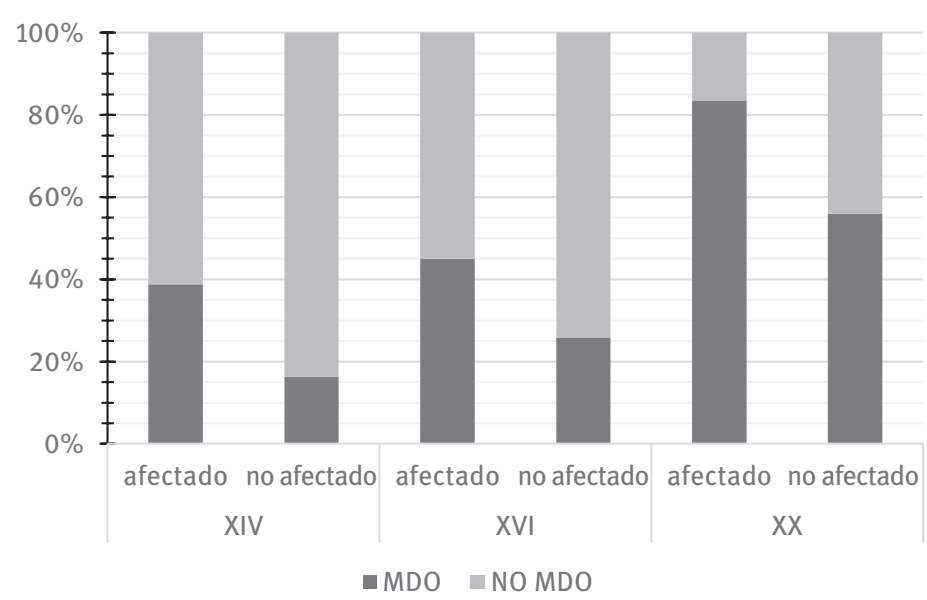

Gráfico 5.5: Frecuencia del MDO en SN indefinidos con respecto al siglo y la afectación.

Tabla 5.6: Frecuencia del MDO en SN indefinidos con respecto al siglo y la afectación.

\begin{tabular}{llrrrr}
\hline & & \multicolumn{2}{c}{ MDO } & \multicolumn{2}{c}{ NO MDO } \\
\hline XIV & afectado & $39 \%$ & $(31 / 80)$ & $61 \%$ & $(49 / 80)$ \\
\cline { 2 - 6 } & no afectado & $16 \%$ & $(13 / 80)$ & $84 \%$ & $(67 / 80)$ \\
\hline XVI & afectado & $45 \%$ & $(54 / 120)$ & $55 \%$ & $(66 / 120)$ \\
\cline { 2 - 6 } & no afectado & $26 \%$ & $(31 / 120)$ & $74 \%$ & $(89 / 120)$ \\
\hline XX & afectado & $84 \%$ & $(167 / 200)$ & $17 \%$ & $(33 / 200)$ \\
\cline { 2 - 6 } & no afectado & $56 \%$ & $(112 / 200)$ & $44 \%$ & $(88 / 200)$ \\
\hline
\end{tabular}


El efecto de la afectación en este caso es evidente y así lo ejemplifican los casos de (102), donde el objeto indirecto afectado de (102a) presenta MDO, a diferencia del de (102b), que no está afectado por la acción del verbo y, por consiguiente, aparece sin marca preposicional.

(102) SN indefinidos del siglo $\mathrm{xx}$

a) La escuadra pretoriana que arrastraba a un hombre livido. (1917, Miró, Figuras de la pasión del Señor, II)

b) Recuerdo un viejecito vestido de negro. (1944-1949, Baroja, Desde la última vuelta del camino. Memorias)

A diferencia de la telicidad, la afectación muestra un claro impacto en el uso del MDO, consistente en que los objetos directos indefinidos afectados favorecen la aparición de la marca preposicional frente a los objetos directos no afectados. Dicho efecto se puede observar en los tres períodos estudiados, pero solo se produce, como se ha mencionado, sobre los SN indefinidos con función de complemento directo, por lo que nos encontramos ante una interacción entre afectación y definitud. Y, de acuerdo con lo expuesto, el análisis estadístico de los datos permite confirmar tanto el efecto significativo de la afectación (estimado: 1,$31 ; \mathrm{p}=0,001$ ), como su interacción con la definitud (estimado: $-1,62$; $\mathrm{p}<0,001)$.

\subsubsection{Telicidad - afectación}

Examinados los efectos de la telicidad y la afectación por separado, se presentan a continuación los resultados relativos a ambos factores de forma conjunta. El objetivo de los Gráficos 5.6 y 5.7, que recogen los resultados correspondientes a los objetos definidos e indefinidos respectivamente, es el de comprobar si existe algún tipo de interacción que pueda explicar con mayor detalle la variación descrita por los resultados independientes de ambos factores. Asimismo, las Tablas 5.7 y 5.8 presentan los valores absolutos correspondientes a cada gráfico.

Las frecuencias relativas de uso del MDO con objetos directos definidos poseen la siguiente distribución: en el siglo XIV presentan marca preposicional el 53\% de los objetos afectados atélicos, el 44\% de los objetos afectados télicos, el 54\% de los objetos no afectados atélicos y el 50\% de los objetos no afectados télicos. En el siglo XVI, la frecuencia de uso de MDO es del $66 \%$ con objetos afectados atélicos, del 63\% con objetos afectados télicos y del 66\% con objetos no afectados, tanto atélicos, como télicos. En lo que al siglo xx se refiere, las frecuen- 
cias ascienden a $97 \%$ para los objetos afectados atélicos, 94\% para los afectados télicos, 93\% en el caso de los objetos no afectados atélicos y, finalmente, 90\% para los no afectados télicos.

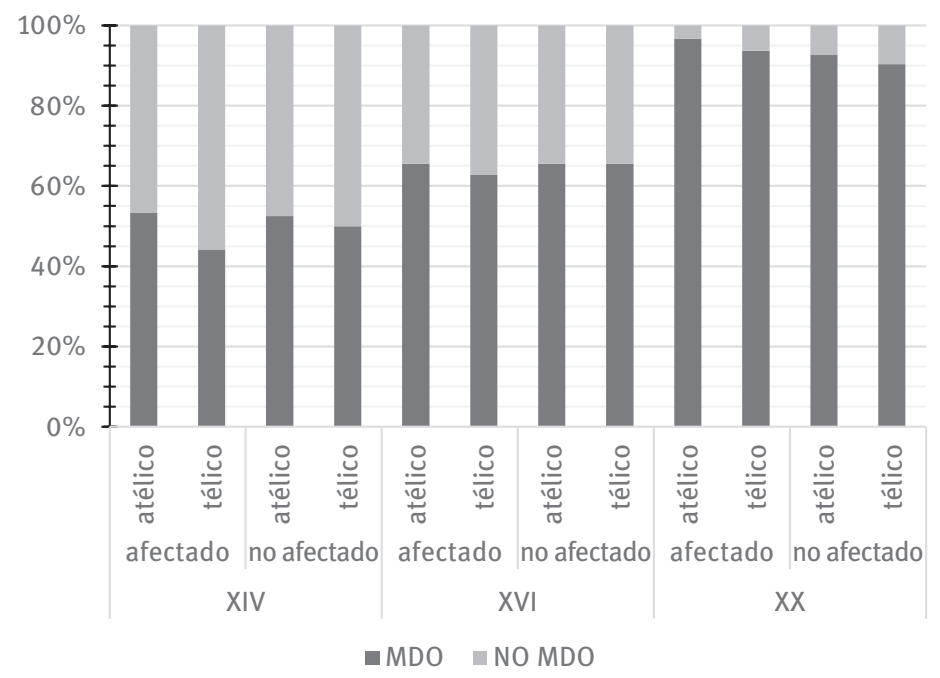

Gráfico 5.6: Frecuencia del MDO en SN definidos con respecto al siglo, la afectación y la telicidad.

Tabla 5.7: Frecuencia del MDO en SN definidos con respecto al siglo, la afectación y la telicidad.

\begin{tabular}{|c|c|c|c|c|c|c|}
\hline \multirow[b]{2}{*}{ XIV } & \multirow[b]{2}{*}{ afectado } & \multirow[b]{2}{*}{ atélico } & \multicolumn{2}{|c|}{ MDO } & \multicolumn{2}{|c|}{ NO MDO } \\
\hline & & & $53 \%$ & $(64 / 120)$ & $47 \%$ & $(56 / 120)$ \\
\hline & & télico & $44 \%$ & $(53 / 120)$ & $56 \%$ & $(67 / 120)$ \\
\hline & no afectado & atélico & $54 \%$ & $(65 / 120)$ & $46 \%$ & $(55 / 120)$ \\
\hline & & télico & $50 \%$ & $(60 / 120)$ & $50 \%$ & $(60 / 120)$ \\
\hline \multirow[t]{4}{*}{ XVI } & afectado & atélico & $66 \%$ & $(119 / 180)$ & $34 \%$ & $(61 / 180)$ \\
\hline & & télico & $63 \%$ & $(113 / 180)$ & $37 \%$ & $(67 / 180)$ \\
\hline & no afectado & atélico & $66 \%$ & $(118 / 180)$ & $34 \%$ & $(62 / 180)$ \\
\hline & & télico & $66 \%$ & $(118 / 180)$ & $34 \%$ & $(62 / 180)$ \\
\hline \multirow[t]{4}{*}{$x x$} & afectado & atélico & $97 \%$ & $(290 / 300)$ & $3 \%$ & $(10 / 300)$ \\
\hline & & télico & $94 \%$ & $(281 / 300)$ & $6 \%$ & $(19 / 300)$ \\
\hline & no afectado & atélico & $93 \%$ & $(278 / 300)$ & $7 \%$ & $(22 / 300)$ \\
\hline & & télico & $90 \%$ & $(271 / 300)$ & $10 \%$ & $(29 / 300)$ \\
\hline
\end{tabular}




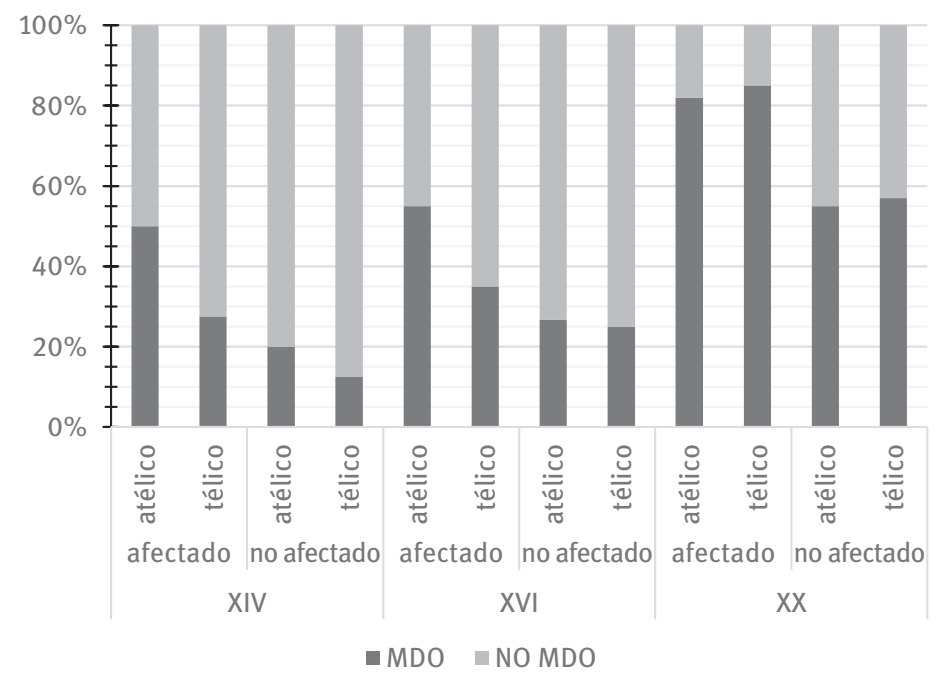

Gráfico 5.7: Frecuencia del MDO en SN indefinidos con respecto al siglo, la afectación y la telicidad.

Tabla 5.8: Frecuencia del MDO en SN indefinidos con respecto al siglo, la afectación y la telicidad.

\begin{tabular}{|c|c|c|c|c|c|c|}
\hline \multirow[b]{2}{*}{ XIV } & \multirow[b]{2}{*}{ afectado } & \multirow[b]{2}{*}{ atélico } & \multicolumn{2}{|c|}{ MDO } & \multicolumn{2}{|c|}{ NO MDO } \\
\hline & & & $50 \%$ & $(20 / 40)$ & $50 \%$ & $(20 / 40)$ \\
\hline & & télico & $28 \%$ & $(11 / 40)$ & $73 \%$ & $(29 / 40)$ \\
\hline & no afectado & atélico & $20 \%$ & $(8 / 40)$ & $80 \%$ & $(32 / 40)$ \\
\hline & & télico & $13 \%$ & $(5 / 40)$ & $88 \%$ & $(35 / 40)$ \\
\hline \multirow[t]{4}{*}{$\mathrm{XVI}$} & afectado & atélico & $55 \%$ & $(33 / 60)$ & $45 \%$ & $(27 / 60)$ \\
\hline & & télico & $35 \%$ & $(21 / 60)$ & $65 \%$ & $(39 / 60)$ \\
\hline & no afectado & atélico & $27 \%$ & $(16 / 60)$ & $73 \%$ & $(44 / 60)$ \\
\hline & & télico & $25 \%$ & $(15 / 60)$ & $75 \%$ & $(45 / 60)$ \\
\hline \multirow[t]{4}{*}{$x X$} & afectado & atélico & $82 \%$ & $(82 / 100)$ & $18 \%$ & $(18 / 100)$ \\
\hline & & télico & $85 \%$ & $(85 / 100)$ & $15 \%$ & $(15 / 100)$ \\
\hline & no afectado & atélico & $55 \%$ & $(55 / 100)$ & $45 \%$ & $(45 / 100)$ \\
\hline & & télico & $57 \%$ & $(57 / 100)$ & $43 \%$ & $(43 / 100)$ \\
\hline
\end{tabular}

Por otro lado, en lo que a los SN indefinidos se refiere, la distribución del MDO alcanza las siguientes frecuencias relativas: en el siglo XIV el 50\% de los objetos directos afectados de predicados atélicos presenta MDO, frente al $28 \%$ de los objetos afectados de predicados télicos y, en cuanto a los objetos no afectados, presenta 
marca preposicional el 20\% de los objetos de predicados atélicos, frente a tan solo al 13\% de los objetos de predicados télicos. En el siglo XVI, la frecuencia de uso de la marca preposicional es del 55\% para los objetos afectados en predicados atélicos, del 35\% para los objetos afectados de predicados télicos, del 27\% para los objetos no afectados de predicados atélicos y del 25\% para los objetos no afectados de predicados télicos. Por último, respecto al siglo xx, los resultados muestran que el 82\% de los objetos directos afectados de predicados atélicos está marcado preposicionalmente, el 85\% de los afectados en predicados télicos, el $55 \%$ de los no afectados en predicados atélicos y el 57\% de los no afectados en predicados télicos.

Mientras que el Gráfico 5.6 únicamente viene a confirmar que ni telicidad ni afectación ejercen ningún tipo de efecto significativo sobre los objetos directos definidos, el Gráfico 5.7, además de corroborar el efecto de la afectación sobre los SN indefinidos, parece arrojar algo de luz sobre la ligera tendencia que se mostraba en los resultados de telicidad consistente en que los predicados atélicos favoreciesen en los siglos XIV y XVI el uso del MDO frente a los predicados télicos. Pues bien, se puede observar que esta ligera tendencia se localiza fundamentalmente en el ámbito de los objetos afectados, con lo que podría tratarse de un efecto de interacción de factores. Sin embargo, tal como ya se mencionó, el efecto de la telicidad sobre los objetos indefinidos no demostró ser estadísticamente significativo y lo mismo ocurre con la interacción entre telicidad y afectación (estimado: 0,$08 ; \mathrm{p}=0,94)$. Por lo tanto, la leve tendencia que favorece el MDO en los objetos afectados en predicados atélicos debe de estar justificada por el efecto individual de alguno de los verbos que componen esta categoría, pero la estadística no parece indicar en ningún caso que esté justificada por la propia telicidad (véase apartado 5.5 para análisis más detallado).

\subsubsection{Otros factores}

Tras la presentación de los resultados relativos a los factores que vertebran este estudio, en este subapartado se incluyen asimismo los resultados obtenidos del análisis de los factores que fueron anotados tras la extracción de casos del corpus, es decir, clase aspectual y aspecto gramatical.

En lo referente a la clase aspectual, en el Gráfico 5.8 aparecen representadas las frecuencias relativas de uso del MDO con los SN determinados y en la Tabla 5.9, los valores absolutos correspondientes. Como puede observarse, en el siglo XIV el MDO presenta una frecuencia relativa del 61\% con estados, del 49\% con actividades, del 44\% con realizaciones y del 50\% con logros. En cuanto al 
siglo XVI, los estados presentan MDO en el 64\% de los casos; las actividades, en el 65\%; las realizaciones, en el 60\%; y los logros, en el 68\%. Por último, el 90\% de los estados aparece con MDO en el siglo xx, el 96\% de las actividades, el 93\% de las realizaciones y el $92 \%$ de los logros.

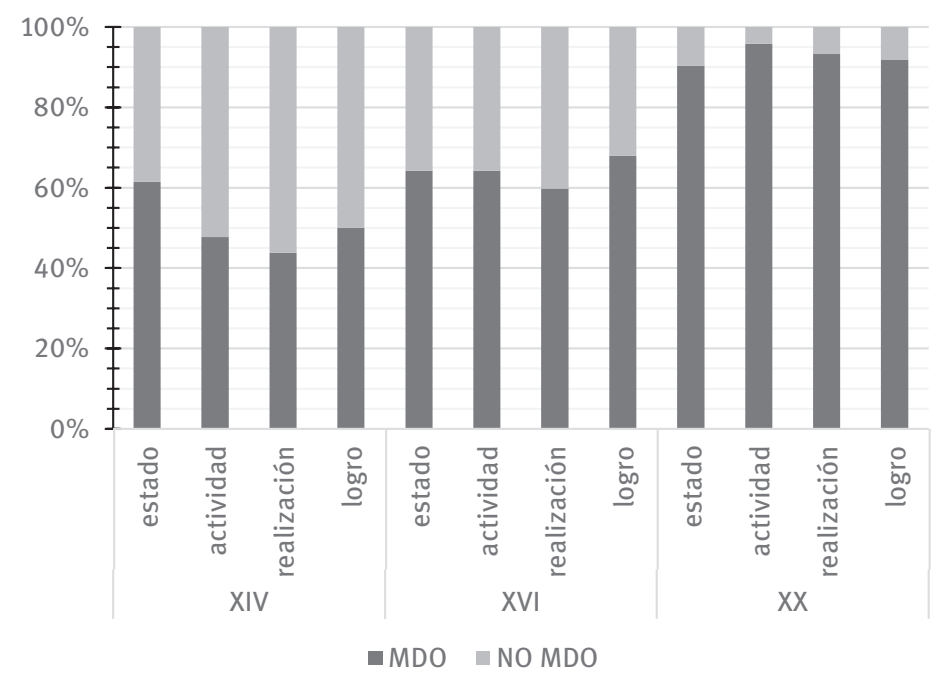

Gráfico 5.8: Frecuencia del MDO en SN definidos con respecto al siglo y la clase aspectual.

Tabla 5.9: Frecuencia del MDO en SN definidos con respecto al siglo y la clase aspectual.

\begin{tabular}{rlrrrr}
\hline & & \multicolumn{2}{c}{ MDO } & \multicolumn{2}{c}{ NO MDO } \\
\hline XIV & estado & $61 \%$ & $(43 / 70)$ & $39 \%$ & $(27 / 70)$ \\
\cline { 2 - 6 } & actividad & $49 \%$ & $(86 / 176)$ & $51 \%$ & $(90 / 176)$ \\
\cline { 2 - 6 } & realización & $44 \%$ & $(28 / 64)$ & $56 \%$ & $(36 / 64)$ \\
\cline { 2 - 6 } & logro & $50 \%$ & $(85 / 170)$ & $50 \%$ & $(85 / 170)$ \\
\hline XVI & estado & $64 \%$ & $(63 / 98)$ & $36 \%$ & $(35 / 98)$ \\
\cline { 2 - 6 } & actividad & $65 \%$ & $(179 / 277)$ & $35 \%$ & $(98 / 277)$ \\
\cline { 2 - 6 } & realización & $60 \%$ & $(61 / 102)$ & $40 \%$ & $(41 / 102)$ \\
\cline { 2 - 6 } & logro & $68 \%$ & $(165 / 243)$ & $32 \%$ & $(78 / 243)$ \\
\cline { 2 - 6 } & estado & $90 \%$ & $(150 / 166)$ & $10 \%$ & $(16 / 166)$ \\
\cline { 2 - 6 } & actividad & $96 \%$ & $(452 / 472)$ & $4 \%$ & $(20 / 472)$ \\
\cline { 2 - 6 } & realización & $93 \%$ & $(125 / 134)$ & $7 \%$ & $(9 / 134)$ \\
\cline { 2 - 6 } & logro & $92 \%$ & $(393 / 428)$ & $8 \%$ & $(35 / 428)$ \\
\hline
\end{tabular}


Los casos recogidos en (103) vienen a mostrar la ausencia de efecto de la clase aspectual sobre el MDO de objetos directos definidos en el siglo XIV. El ejemplo de (103a) contiene un verbo de actividad y no presenta marca preposicional en su objeto; sin embargo, (103b) posee un verbo de realización y, a pesar de tratarse de una clase aspectual inherentemente télica, tampoco presenta MDO.

(103) SN definidos del siglo XIV sin MDO

a) Los que atormentaron sus súbditos sin culpa.

(1378-1406, López de Ayala, Rimado de Palacio)

b) Truxieron la niña ante el altar. (1300, Anónimo, El caballero del cisne)

En lo que respecta a los SN indefinidos, tal y como muestran el Gráfico 5.9 y la Tabla 5.10, los estados en el siglo XIv presentan una frecuencia relativa de uso del MDO del 23\%, las actividades, del 40\%; las realizaciones, del 9\%; y los logros, del $22 \%$. En el siglo XVI la frecuencia relativa del MDO es del 20\% para los estados, del 50\% para las actividades, del 33\% para las realizaciones y del 28\% en el caso de los logros. Y, por último, en el siglo xx, los estados presentan MDO en un $40 \%$ de los casos; las actividades, en un $82 \%$; las realizaciones, en un $86 \%$; y los logros, en un 66\% (103/157) de los casos.

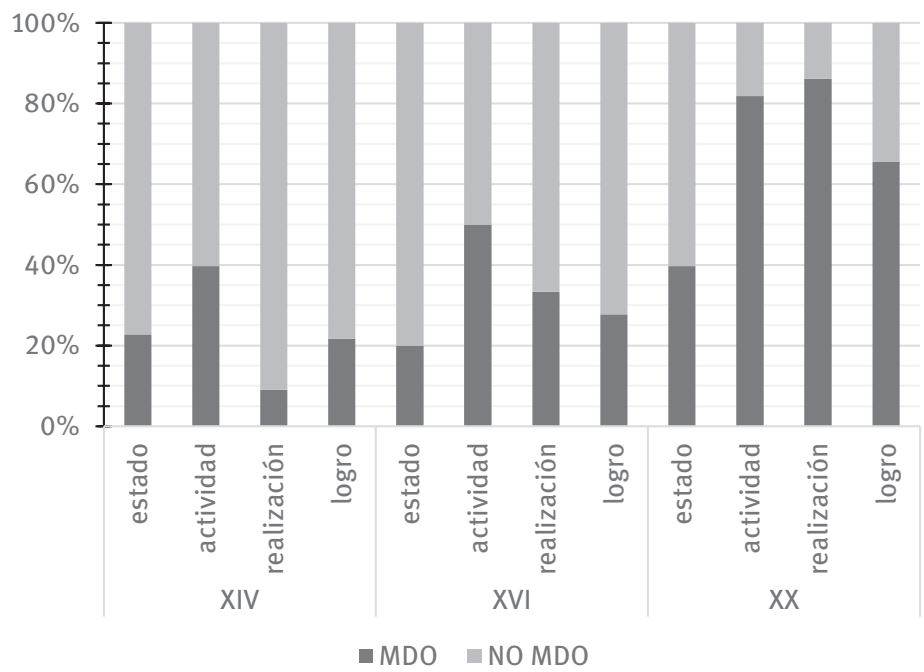

Gráfico 5.9: Frecuencia del MDO en SN indefinidos con respecto al siglo y la clase aspectual. 
Tabla 5.10: Frecuencia del MDO en SN indefinidos con respecto al siglo y la clase aspectual.

\begin{tabular}{rlrrrr}
\hline & & \multicolumn{2}{c}{ MDO } & \multicolumn{2}{c}{ NO MDO } \\
\hline XIV & estado & $23 \%$ & $(43 / 70)$ & $77 \%$ & $(27 / 70)$ \\
\cline { 2 - 6 } & actividad & $40 \%$ & $(86 / 176)$ & $60 \%$ & $(90 / 176)$ \\
\cline { 2 - 6 } & realización & $9 \%$ & $(28 / 64)$ & $91 \%$ & $(36 / 64)$ \\
\cline { 2 - 6 } & logro & $22 \%$ & $(85 / 170)$ & $78 \%$ & $(85 / 170)$ \\
\hline XVI & estado & $64 \%$ & $(63 / 98)$ & $36 \%$ & $(35 / 98)$ \\
\cline { 2 - 6 } & actividad & $50 \%$ & $(179 / 277)$ & $50 \%$ & $(98 / 277)$ \\
\cline { 2 - 6 } & realización & $33 \%$ & $(61 / 102)$ & $67 \%$ & $(41 / 102)$ \\
\cline { 2 - 6 } & logro & $28 \%$ & $(165 / 243)$ & $72 \%$ & $(78 / 243)$ \\
\cline { 2 - 6 } & estado & $40 \%$ & $(150 / 166)$ & $60 \%$ & $(16 / 166)$ \\
\cline { 2 - 6 } & actividad & $82 \%$ & $(452 / 472)$ & $18 \%$ & $(20 / 472)$ \\
\cline { 2 - 6 } & realización & $86 \%$ & $(125 / 134)$ & $14 \%$ & $(9 / 134)$ \\
\cline { 2 - 6 } & logro & $66 \%$ & $(393 / 428)$ & $34 \%$ & $(35 / 428)$ \\
\hline
\end{tabular}

Los ejemplos recogidos en (104) pretenden ilustrar la ausencia de un efecto significativo de la clase aspectual sobre los objetos directos indefinidos. Para ello, se han escogido dos casos pertenecientes al siglo xx en los que el objeto directo aparece con MDO en ambos casos, independientemente de la clase aspectual de su núcleo. Así pues, tanto (104a), donde el núcleo es una actividad, como (104b), que incluye una realización, presentan la marca preposicional en el objeto directo.

(104) SN indefinidos del siglo XX con MDO

a) Tuvo el valor de apalear a un viejo zapatero. (1986, Farner, Flor de sal)

b) Despedazó a un mozalbillo rubio. (1982, Gómez Ojea, Cantiga de agüero)

Observando los resultados obtenidos con respecto a la clase aspectual a la que pertenece el verbo que funciona como núcleo en cada caso, la conclusión que se alcanza es similar a la obtenida para la telicidad. Por un lado, con los objetos directos definidos no se aprecia ningún efecto; por otro lado, los objetos directos indefinidos sí parecen mostrar un grado más elevado de variación entre las distintas clases aspectuales; sin embargo, el análisis estadístico no confirma la significatividad de dicha variación en ningún caso. No obstante, a pesar de la falta de significatividad, puede apreciarse en el Gráfico 5.9 que las actividades 
presentan en los tres siglos analizados frecuencias de MDO relativamente altas o, en cualquier caso, superiores a las que se esperarían en una clase de verbos inherentemente atélica. La razón de que este hecho no resulte estadísticamente significativo puede ser que lo provoquen determinados verbos pertenecientes a la clase de las actividades que seleccionan objetos con MDO desde época temprana debido a algún otro factor que no se haya controlado en el estudio. Esta posibilidad se contempla en el siguiente apartado, dedicado al análisis de los datos.

Finalmente, se presentan los resultados obtenidos en relación con el aspecto gramatical en las Figuras 5.10 y 5.11, con objetos definidos e indefinidos, respectivamente. Las correspondientes frecuencias absolutas se recogen en las Tablas 5.11 y 5.12. Así pues, en el primer gráfico es posible observar que en el siglo XIV los verbos imperfectivos presentan un objeto marcado preposicionalmente en el 52\% de los casos, frente al 51\% de los verbos perfectivos. En lo que respecta al siglo XVI, el MDO presenta una frecuencia absoluta del 61\% con los verbos imperfectivos, mientras que asciende al $72 \%$ con los verbos perfectivos. Y en el siglo xx, los verbos imperfectivos poseen MDO en su objeto directo en el 93\% de los casos, al igual que los verbos perfectivos.

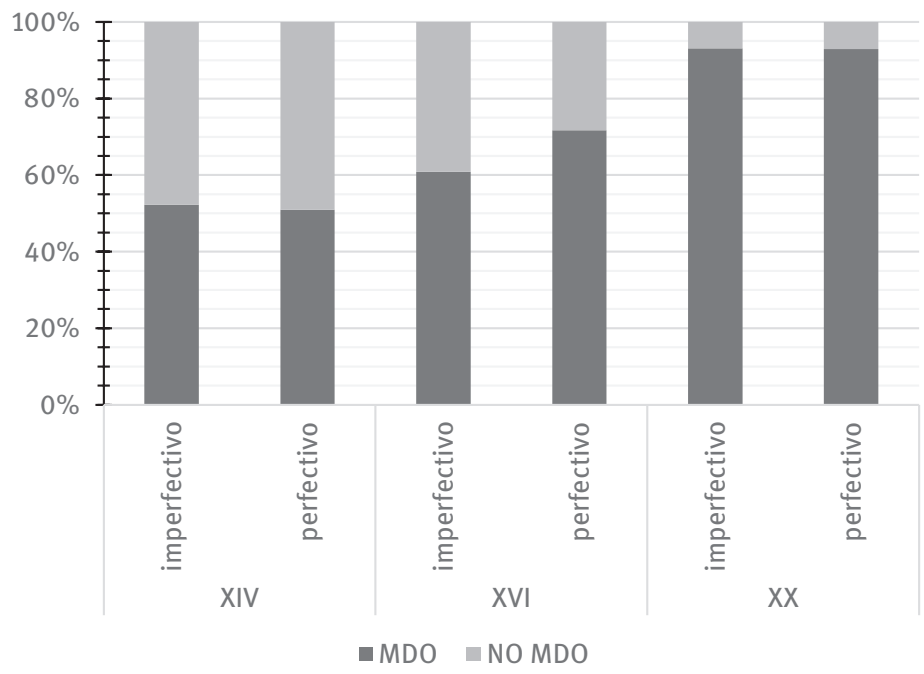

Gráfico 5.10: Frecuencia del MDO en SN definidos con respecto al siglo y al aspecto gramatical.

El aspecto gramatical no muestra ningún efecto significativo sobre el MDO en los objetos directos definidos, pues la ligera tendencia que se aprecia en el siglo XVI no queda confirmada por el análisis estadístico. Los ejemplos de arrastrar en (105) pretenden representar esta ausencia de impacto y para ello se incluyen dos 
Tabla 5.11: Frecuencia del MDO en SN definidos con respecto al siglo y al aspecto gramatical.

\begin{tabular}{llrrrr}
\hline & & \multicolumn{2}{c}{ MDO } & \multicolumn{2}{c}{ NO MDO } \\
\hline XIV & imperfectivo & $52 \%$ & $(118 / 226)$ & $48 \%$ & $(108 / 226)$ \\
\cline { 2 - 6 } & perfectivo & $51 \%$ & $(81 / 159)$ & $49 \%$ & $(78 / 159)$ \\
\hline$X V I$ & imperfectivo & $61 \%$ & $(207 / 340)$ & $39 \%$ & $(133 / 340)$ \\
\cline { 2 - 6 } & perfectivo & $72 \%$ & $(172 / 240)$ & $28 \%$ & $(68 / 240)$ \\
\hline$X X$ & imperfectivo & $93 \%$ & $(581 / 624)$ & $7 \%$ & $(43 / 624)$ \\
\cline { 2 - 6 } & perfectivo & $93 \%$ & $(236 / 254)$ & $7 \%$ & $(18 / 254)$ \\
\hline
\end{tabular}

casos del siglo xx con diferente aspecto gramatical en los cuales el objeto directo definido aparece marcado con la preposición, independientemente de la perfectividad del tiempo.

(105) SN definidos del siglo XX con MDO

a) Arrastraba a su hija.

(1911, Baroja, Las inquietudes de Shanti Andía)

b) Y el hombre [...] arrastró al artista.

(1914, Trigo, Los abismos)

En lo que a los SN indefinidos respecta, la frecuencia relativa de verbos imperfectivos con MDO asciende al 24\% en el siglo XIV, frente al $25 \%$ de los verbos perfectivos; en el siglo XVI, el 33\% de los verbos imperfectivos presentan MDO en su objeto directo y el 31\% de los verbos perfectivos; y, en el siglo xx, la frecuencia relativa de uso del MDO con verbos imperfectivos es del 63\%, frente al $70 \%$ en el caso de los verbos perfectivos.

Los casos de (106) reproducen la falta de impacto del aspecto gramatical. Tanto (106a) como (106b) carecen de MDO a pesar de presentar aspecto imperfectivo y perfectivo, respectivamente.

(106) SN indefinidos del siglo XIV sin MDO

a) Los de sauaruaym quemauan sus fijos enel fuego.

(1300, Anónimo, Biblia Escorial)

b) Quemo sus fijos en fuego segunt la costumbre. (1300, Anónimo, Biblia Escorial)

Los resultados respecto al posible impacto del aspecto gramatical en el MDO, por lo tanto, son claros: la distinción entre aspecto perfectivo e imperfectivo en 


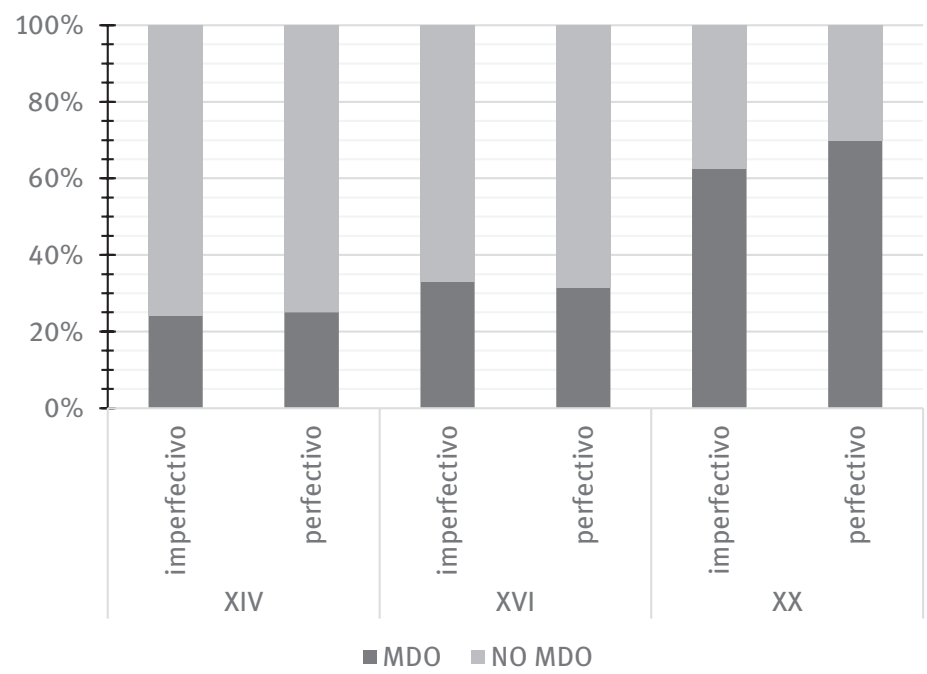

Gráfico 5.11: Frecuencia del MDO en SN indefinidos con respecto al siglo y al aspecto gramatical.

Tabla 5.12: Frecuencia del MDO en SN indefinidos con respecto al siglo y al aspecto gramatical.

\begin{tabular}{llrrrr}
\hline & & \multicolumn{2}{c}{ MDO } & \multicolumn{2}{c}{ NO MDO } \\
\hline XIV & imperfectivo & $24 \%$ & $(20 / 83)$ & $76 \%$ & $(63 / 83)$ \\
\cline { 2 - 6 } & perfectivo & $25 \%$ & $(13 / 52)$ & $75 \%$ & $(39 / 52)$ \\
\hline XVI & imperfectivo & $33 \%$ & $(32 / 97)$ & $67 \%$ & $(65 / 97)$ \\
\cline { 2 - 6 } & perfectivo & $31 \%$ & $(34 / 108)$ & $69 \%$ & $(74 / 108)$ \\
\hline XX & imperfectivo & $63 \%$ & $(119 / 190)$ & $37 \%$ & $(71 / 190)$ \\
\cline { 2 - 6 } & perfectivo & $70 \%$ & $(63 / 90)$ & $30 \%$ & $(27 / 90)$ \\
\hline
\end{tabular}

los verbos no influye en la aparición del MDO en español en ninguno de los tres períodos analizados, ni con los objetos definidos, ni con los indefinidos (estimado: 0,$05 ; \mathrm{p}=0,91$.

\subsection{Análisis}

Los resultados del estudio de corpus presentados en el apartado previo confirman solo parte de las hipótesis propuestas en el apartado 5.2, recogidas de nuevo en (107). 
(107) Hipótesis

H1: Los objetos directos de predicados télicos presentan con mayor frecuencia MDO que los objetos directos de predicados atélicos.

H2: Los objetos directos afectados por la acción del verbo presentan con mayor frecuencia MDO que los objetos no afectados.

En lo que respecta a la primera hipótesis, la telicidad no ha mostrado ningún impacto significativo en la aparición del MDO con objetos directos de referente humano según los resultados obtenidos. El análisis de corpus ha revelado que el impacto de la telicidad es mínimo o inexistente, no solo en el siglo $\mathrm{xx}$, sino también en etapas previas del español, donde se reduce a ligeras tendencias, que se analizan más adelante en este apartado. Este hecho pone en tela de juicio la idea de que la telicidad desempeña un papel fundamental en el MDO.

En relación con estos resultados, cabe mencionar los obtenidos por Barraza Carbajal (2008) en su estudio diacrónico acerca del impacto de la semántica verbal en el marcado preposicional. Dicho estudio aborda el efecto que tanto el aspecto léxico como el aspecto gramatical ejercen sobre el MDO con objetos directos inanimados. Sobre el planteamiento que realiza acerca del aspecto léxico, existen algunas diferencias en relación con el análisis presentado en este capítulo. En primer lugar, Barraza considera únicamente la telicidad inherente a las distintas clases aspectuales; en segundo lugar, se limita a asociar los conceptos de telicidad y afectación, sin entrar a valorar casos en los que estos factores puedan aparecer de forma disociada; y, por último, no distingue la definitud de los objetos directos que se incluyen en el estudio. Sin embargo, lo interesante es que, a pesar de todo, los resultados que presenta Barraza apuntan en la misma dirección que los obtenidos en el presente estudio para los objetos directos humanos indefinidos, en lo que a telicidad se refiere. Los datos que aporta la autora aparecen recogidos en la Tabla 5.13 y representados en el Gráfico 5.12. Tal y como se puede apreciar, la telicidad no parece ser un factor relevante en la explicación del MDO en español; sin embargo, se observa una ligera tendencia que sugiere que serían los verbos atélicos los que, en caso de que el efecto fuese significativo, favorecerían el MDO por encima de los verbos télicos. Dicha tendencia se puede apreciar con mayor claridad en el siglo XVIII según los resultados de Barraza. A pesar de todo, el MDO con objetos inanimados aparece de forma muy excepcional y de los 2260 objetos directos que Barraza extrae de su corpus, tan solo 281 aparecen con preposición, por lo que los resultados que presenta solo pueden ser tenidos en cuenta para señalar tendencias, pero no para establecer generalizaciones en ningún caso. 


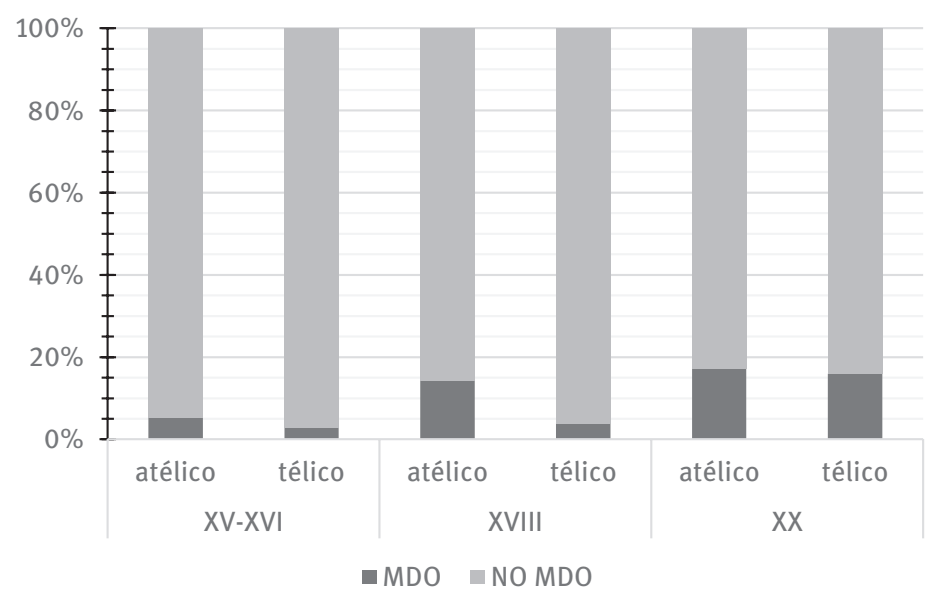

Gráfico 5.12: Frecuencia del MDO con respecto al siglo y la telicidad (adaptado de Barraza 2008, 345).

Tabla 5.13: Frecuencia del MDO con respecto al siglo y la telicidad (adaptado de Barraza 2008, 345).

\begin{tabular}{llrrrr}
\hline & & \multicolumn{2}{c}{ MDO } & \multicolumn{2}{c}{ NO MDO } \\
\hline XIV & atélico & $5 \%$ & $(18 / 344)$ & $95 \%$ & $(326 / 344)$ \\
\cline { 2 - 6 } & télico & $3 \%$ & $(6 / 215)$ & $97 \%$ & $(209 / 215)$ \\
\hline XVI & atélico & $14 \%$ & $(67 / 471)$ & $86 \%$ & $(404 / 471)$ \\
\cline { 2 - 6 } & télico & $4 \%$ & $(5 / 132)$ & $96 \%$ & $(127 / 132)$ \\
\hline XX & atélico & $17 \%$ & $(133 / 772)$ & $83 \%$ & $(639 / 772)$ \\
\cline { 2 - 6 } & télico & $16 \%$ & $(52 / 326)$ & $84 \%$ & $(274 / 326)$ \\
\hline
\end{tabular}

Volviendo a las hipótesis, y a diferencia de lo que ocurre con la primera, la segunda hipótesis ha quedado parcialmente confirmada. La afectación ha demostrado funcionar como un factor relevante que condiciona el uso del MDO, aunque únicamente cuando el objeto directo está constituido por un SN indefinido. Así pues, la afectación se postula como un factor que interactúa con la definitud, subordinándose a ella al ejercer su efecto únicamente en los SN indefinidos. En sincronía, cabría la hipótesis de que la afectación es relevante solo con SN indefinidos puesto que estos constituyen la única zona de variación a día de hoy, ya que en los SN definidos el marcado es obligatorio; sin embargo, hay que descartar esta hipótesis, pues el impacto de la afectación se ha mantenido constante tan solo en los indefinidos a lo largo de los tres períodos estudiados, es decir, que en el siglo XIV 
tampoco condicionaba el MDO en los SN definidos, cuando la obligatoriedad del marcado aún se restringía únicamente a pronombres y nombres propios.

Los resultados respecto a la afectación apuntan en la misma dirección que los obtenidos por von Heusinger/Kaiser (2011) en su trabajo acerca del impacto de este factor en la diacronía del MDO. Dicho estudio toma las clases de verbos definidas en la escala de afectación de Tsunoda (1985) para comprobar si presentan algún impacto en el uso de la marca preposicional desde una perspectiva diacrónica. Sus resultados señalan que la diferencia de comportamiento de las distintas clases verbales es significativa tanto con los SN definidos, como con los indefinidos. Sin embargo, en el caso de los objetos directos definidos, no se puede hablar de diferencia significativa entre las cinco clases tenidas en cuenta, sino únicamente entre dos bloques a los que se adscriben unas y otras. Además, la diferencia que se muestra entre el bloque de las clases verbales que implican mayor grado de afectación y el de las que implican un grado menor es más reducida en los SN definidos que en los SN indefinidos. Así pues, los resultados del presente análisis apuntan en la misma dirección de los de Heusinger/Kaiser al señalar la afectación del objeto como un factor relevante en el desarrollo diacrónico del MDO en español, a pesar de que dicha relevancia no haya sido confirmada en los SN definidos por el estudio presentado en este capítulo.

Ahora bien, una vez evaluadas las hipótesis relativas a los factores que vertebran el estudio, es interesante añadir algunos comentarios acerca de los resultados obtenidos con respecto a la definitud y al resto de factores descritos a posteriori en los casos extraídos del corpus.

Como ya se anticipaba en el apartado anterior, en lo que a la definitud se refiere, los resultados de esta investigación han apuntado exactamente en la misma dirección que los obtenidos en estudios previos como los de Laca (2006) y Company Company (2002a). No obstante, las frecuencias de MDO que este trabajo ha recogido con los SN indefinidos son más elevadas que las que apunta el estudio de Laca, que es la única que realiza la distinción entre definidos e indefinidos. Este hecho, como se ha señalado, puede ser debido muy probablemente a la propia extensión de la investigación realizada, que duplica exactamente el número de SN indefinidos que contemplaba Laca; y, por ello, los datos presentados han conseguido capturar quizá con mayor precisión la diferencia de marcado entre definidos e indefinidos. Sea como fuere, la evolución del MDO que se aprecia en cualquiera de los estudios mencionados se desarrolla de una manera francamente similar.

El siguiente factor que cabe mencionar es la clase aspectual de los verbos, que ha sido anotada con la intención de confirmar las ideas que estudios previos han propuesto para abordar la relación entre el aspecto léxico y el MDO en español. Dichos trabajos apuntan a la telicidad intrínseca de determinadas 
clases de verbos como factor fundamental para explicar la marcación preposicional del objeto directo. Sin embargo, las frecuencias de uso del marcado preposicional con las distintas clases aspectuales de verbos no han revelado ningún efecto significativo ni en el caso de los SN definidos, ni en el de los indefinidos. Estos resultados, en primera instancia, parecen cuestionar la idea defendida en Torrego $(1998 ; 1999)$ de que los verbos inherentemente télicos implican la marca preposicional; pero, si bien es cierto que no la secundan, tampoco la invalidan completamente. Como se explica en el capítulo 2, una de las afirmaciones de Torrego acerca del MDO sostiene que los verbos télicos implican la marca preposicional del objeto directo. Hay que tener en cuenta que dicha afirmación se realiza desde una perspectiva sincrónica y, por lo tanto, solo podría contrastarse con los datos obtenidos para el siglo xx del presente estudio. Así pues, si observamos los resultados referentes a los SN definidos, Torrego podría estar en lo cierto, pues realizaciones y logros se marcan en casi la totalidad de los casos. Por otro lado, esto no es lo que se observa para los SN indefinidos, donde la frecuencia de marcado es muy alta en el caso de las realizaciones, pero no lo es tanto para los logros, donde asciende únicamente hasta el 66\% de los casos. En los ejemplos del siglo xx recogidos en (108) se presentan algunos casos de verbos télicos, como matar, quemar o hallar, cuyos objetos, tanto definidos, como indefinidos, no presentan MDO.

(108) Verbos télicos sin MDO

a) La llama quemó los impios. (1909, Anónimo, Biblia Reina-Valera)

b) Matasteis sus hijos. (1909, Anónimo, Biblia Reina-Valera)

c) Matando cuatro soldados que estaban de guardia. (1905-1907, Coloma, Jeromín)

d) Halló un cabrero viejo, peludo y de bizco mirar. (1909, Pérez Galdós, El caballero encantado)

Por lo tanto, los datos conducen a matizar la idea de que los verbos télicos imponen la marca preposicional en su objeto directo, pudiéndose decir en su lugar que dichos verbos lo que presentan es una elevada frecuencia de uso del MDO.

En lo que a los verbos atélicos se refiere, Torrego defiende que el MDO no es obligatorio con estados y actividades; sin embargo, en caso de aparecer con este tipo de verbos, la interpretación de dichos predicados pasaría a ser télica, es decir, el MDO con verbos atélicos implica la telicidad del predicado. No obstante, las frecuencias de marcado de los objetos directos con estados y actividades, independientemente de su magnitud, no cuestionan la idea de Torrego 
puesto que su trabajo en ningún momento hace referencia a la frecuencia con que estas clases aspectuales aparecen con la marca preposicional, sino únicamente a la interpretación que el predicado adquiere en estos casos. Por lo tanto, ya que de los datos cuantitativos no se puede extraer suficiente información para afrontar el planteamiento que defiende Torrego, se intentará abordar a través de datos cualitativos utilizando ejemplos concretos del estudio. En este punto, es importante advertir que un análisis de corpus dificulta en sumo grado realizar apreciaciones relacionadas con la interpretación de los ejemplos, puesto que, a no ser que algún adjunto lo indique de forma explícita, es muy difícil conocer qué interpretación pretende expresar el autor del texto en cada caso. Sin embargo, ha sido posible encontrar algún ejemplo con el que poder ilustrar las condiciones anteriormente descritas. En (109a) un verbo de actividad, maltratar, aparece acompañado de un objeto directo con MDO y de un adjunto introducido por la preposición durante, que informa del período a lo largo del cual tiene lugar la acción descrita por el verbo. Siguiendo el planteamiento defendido por Torrego, se trataría del caso de un verbo atélico cuyo predicado adquiere una lectura télica iterativa al presentar MDO. A pesar de ello, si se aplica la prueba de telicidad, es decir, si el adjunto encabezado por durante es sustituido por uno que delimite el evento, el resultado que se obtiene es agramatical (109b). Este hecho conduce a pensar que la (a)telicidad de este ejemplo es independiente del uso del MDO y que en (109a) el adjunto introducido por durante lo que hace es reforzar precisamente la lectura atélica del verbo.

(109) Verbo de actividad con MDO

a) Un escritor huido de la URSS maltrató a su hijo durante el último año de convivencia.

(1977, Vázquez Montalbán, La soledad del mánager)

b) *Un escritor huido de la URSS maltrató a su hijo en un año de convivencia.

Asimismo, otro ejemplo que pondría en tela de juicio la idea asumida por Torrego sería el planteado en (110). En este caso, un verbo de actividad como arrastrar, que es intrínsecamente atélico, debería obtener una lectura télica cuando su objeto directo apareciese con la marca preposicional. A primera vista, este parece ser el caso, pues no surge ningún problema cuando se aplica sobre él la prueba de telicidad, como refleja (110a). Sin embargo, (110b) revela que la telicidad del ejemplo no se deriva del MDO, sino del adjunto que introduce la meta del evento (hasta las gradas de la catedral). Si dicho adjunto desaparece, el predicado pierde su interpretación télica, a pesar de continuar presentando MDO, y la prueba de telicidad produce un resultado agramatical. 
(110) Verbo de actividad con MDO

a) Amal arrastró a su amigo hasta las gradas de la catedral (en dos minutos). (1930, Fernández Flórez, Fantasmas)

b) Arnal arrastró a su amigo ( ${ }^{*}$ en dos minutos).

Por lo tanto, los casos extraídos del corpus conducen a cuestionar el carácter del MDO con verbos atélicos como desencadenante de una interpretación télica del predicado. Como se ha demostrado, los verbos atélicos mantienen su lectura natural a pesar de la marca preposicional y, en caso de presentar una interpretación télica, esta no parece desprenderse del propio MDO, como defiende Torrego.

Por último, respecto a la clase aspectual de los verbos, es interesante, asimismo, comentar el hecho de que las actividades han presentado en los SN indefinidos unas frecuencias de objeto marcado quizá inesperadamente elevadas, teniendo en cuenta su condición de clase aspectual inherentemente atélica. Es interesante profundizar en la causa de por qué las actividades presentan esos niveles de MDO y, por ello, en el Gráfico 5.13 aparece representada la frecuencia relativa de uso del marcador atendiendo a la interacción de la clase aspectual con la afectación ( $\tan$ solo en SN indefinidos que es dónde destacan las actividades). Los valores absolutos correspondientes pueden observarse en la Tabla 5.14.

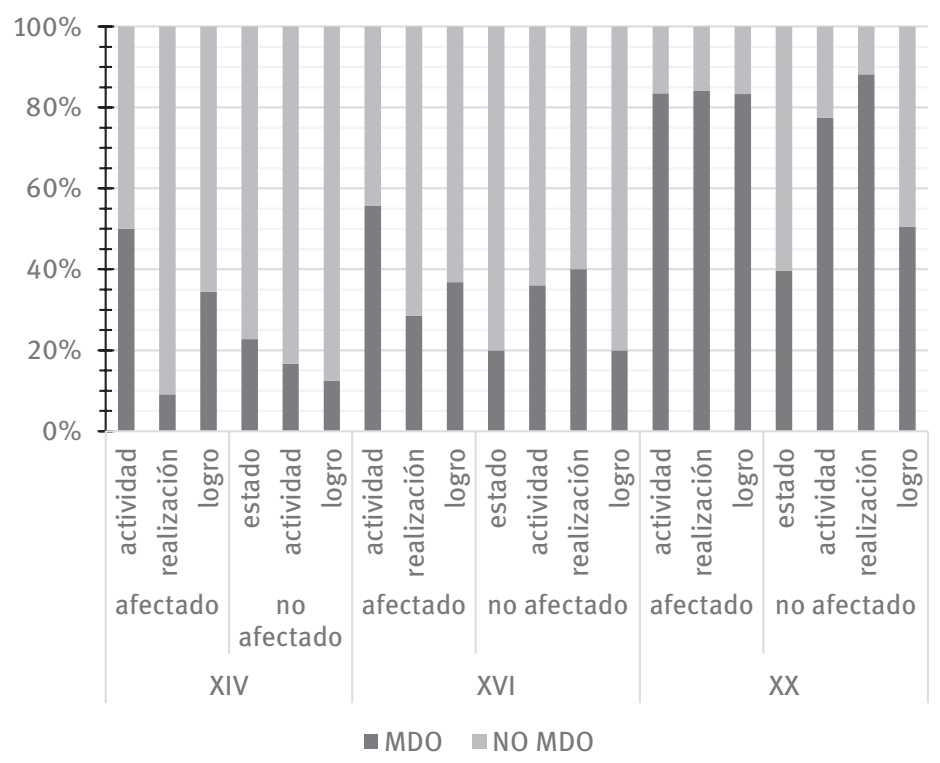

Gráfico 5.13: Frecuencia del MDO en SN indefinidos con respecto al siglo, la afectación y la clase aspectual. 
Tabla 5.14: Frecuencia del MDO en SN indefinidos con respecto al siglo, la afectación y la clase aspectual.

\begin{tabular}{|c|c|c|c|c|c|c|}
\hline \multirow[b]{2}{*}{ XIV } & \multirow[b]{2}{*}{ afectado } & \multirow[b]{2}{*}{ actividad } & \multicolumn{2}{|c|}{ MDO } & \multicolumn{2}{|c|}{ NO MDO } \\
\hline & & & $50 \%$ & $(20 / 40)$ & $50 \%$ & $(20 / 40)$ \\
\hline & & realización & $9 \%$ & $(1 / 11)$ & $91 \%$ & $(10 / 11)$ \\
\hline & & logro & $34 \%$ & $(10 / 29)$ & $66 \%$ & $(19 / 29)$ \\
\hline & no afectado & estado & $23 \%$ & $(5 / 22)$ & $77 \%$ & $(17 / 22)$ \\
\hline & & actividad & $17 \%$ & $(3 / 18)$ & $83 \%$ & $(15 / 18)$ \\
\hline & & logro & $13 \%$ & $(5 / 40)$ & $88 \%$ & $(35 / 40)$ \\
\hline \multirow[t]{7}{*}{$\mathrm{XVI}$} & afectado & actividad & $56 \%$ & $(34 / 61)$ & $44 \%$ & $(27 / 61)$ \\
\hline & & realización & $29 \%$ & $(6 / 21)$ & $71 \%$ & $(15 / 21)$ \\
\hline & & logro & $37 \%$ & $(14 / 38)$ & $63 \%$ & $(24 / 38)$ \\
\hline & no afectado & estado & $20 \%$ & $(7 / 35)$ & $80 \%$ & $(28 / 35)$ \\
\hline & & actividad & $36 \%$ & $(9 / 25)$ & $64 \%$ & $(16 / 25)$ \\
\hline & & realización & $40 \%$ & $(6 / 15)$ & $60 \%$ & $(9 / 15)$ \\
\hline & & logro & $20 \%$ & $(9 / 45)$ & $80 \%$ & $(36 / 45)$ \\
\hline \multirow[t]{7}{*}{$X X$} & afectado & actividad & $83 \%$ & $(91 / 109)$ & $17 \%$ & $(18 / 109)$ \\
\hline & & realización & $84 \%$ & $(16 / 19)$ & $16 \%$ & $(3 / 19)$ \\
\hline & & logro & $83 \%$ & $(60 / 72)$ & $17 \%$ & $(12 / 72)$ \\
\hline & no afectado & estado & $40 \%$ & $(23 / 58)$ & $60 \%$ & $(35 / 58)$ \\
\hline & & actividad & $78 \%$ & $(31 / 40)$ & $23 \%$ & $(9 / 40)$ \\
\hline & & realización & $88 \%$ & $(15 / 17)$ & $12 \%$ & $(2 / 17)$ \\
\hline & & logro & $51 \%$ & $(43 / 85)$ & $49 \%$ & $(42 / 85)$ \\
\hline
\end{tabular}

Como puede observarse tanto en el gráfico como en la tabla, las actividades que realmente destacan son aquellas que implican la afectación del objeto, es decir, verbos como apalear, apedrear, arrastrar o azotar. Aunque en el siglo xx se comportan de manera exactamente igual al resto de verbos con objeto afectado, en los siglos XIV y XVI llegan a destacar incluso frente a las realizaciones y los logros que también implican la afectación de sus respectivos objetos.

Una explicación bastante plausible podría derivarse del tipo de afectación que reciben los objetos. Mientras que en la mayoría de las actividades que implican afectación, se trata de una afectación que conlleva un daño físico, como en los casos mencionados de apalear, apedrear o azotar; muchos casos de verbos de realización o de logro que se han extraído del corpus simplemente implican un cambio de lugar. Este sería el caso de verbos como traer o enviar. Por lo tanto, la percepción de un grado más fuerte de afectación con los verbos de actividad previsiblemente es lo que ha debido provocar sus mayores frecuencias de marcado; 
de hecho, en las actividades que no implican afectación no se observa dicho comportamiento. Todo ello se puede apreciar en los ejemplos de (111), donde se observa como los verbos de actividad que implican afectación, como los de $(111 \mathrm{a}-\mathrm{c})$ generalmente han aparecido con MDO, mientras que las realizaciones y los logros no han presentado el marcado con tanta frecuencia, tal como ocurre en (111d-e).

(111) Actividades, realizaciones y logros que implican objetos afectados

a. Alexandre Severo [.. . ] a cierto soldado porque apaleó a una vieja huéspeda suya le castigó

(1594, Villegas, Fructus sanctorum y quinta parte del Flossanctorum)

b. estando él en Roma vio apedrear a un sacerdote griego (1539, Guevara, Menosprecio de corte y alabanza de aldea)

c. Un caballero azotó a un paje por un enojo que le hizo (1574, Santa Cruz de Dueñas, Floresta española)

d. embió una su fija pequeñuela que la criasse en su casa (1300-1305, Anónimo, Libro del Cavallero Cifar)

e. De allí se fue luego la reina y mandó traer un pelegrino que allí avía venido (1500, Anónimo, Libro del conde Partinuplés)

Asimismo, esta sería la causa que subyace al hecho de que los predicados atélicos con objetos afectados mostrasen una ligera tendencia a favorecer el uso del MDO, tal como señalaban los resultados producto de la interacción entre la telicidad y la afectación en los SN indefinidos, representados en el Gráfico 5.7. Si bien es cierto que todos los verbos de actividad no se corresponden con predicados atélicos, puesto que pueden intervenir otros constituyentes que introduzcan un límite en el evento, la correlación entre actividades y atelicidad es bastante considerable.

Esta explicación para el comportamiento de las actividades vendría a confirmar aún con mayor fuerza, por un lado, la relevancia de la afectación como factor que influye en el MDO y, por otro lado, el escaso o nulo efecto que ejerce sobre el fenómeno la telicidad.

Para concluir, de los factores tenidos en cuenta en el estudio, tan solo quedaría comentar los resultados que conciernen al aspecto gramatical. La información relativa a dicho factor ha sido anotada en los casos de estudio puesto que el aspecto gramatical se ha postulado en diversas ocasiones como elemento que interactúa con la clase aspectual y contribuye a la construcción de la telicidad del predicado (Miguel 1999). En esta línea, Barraza (2008), en su estudio diacrónico de cómo influye la semántica del verbo en los objetos directos inanimados, también incluye el aspecto gramatical para determinar su influencia sobre el fenómeno del MDO y, según su estudio, defiende que «existe una marcada prefe- 
rencia en español porque las oraciones con objeto directo presenten un bajo nivel de transitividad, manifestado a través de núcleos verbales no perfectivos» (2008, 347). Estos resultados obtenidos para los objetos directos inanimados contrastan con los obtenidos en el presente análisis de corpus, en el que se ha mostrado que el aspecto gramatical del núcleo verbal no ejerce ningún efecto significativo sobre la aparición del MDO. A pesar de todo, como ya se ha señalado anteriormente, el reducido número de casos con marca preposicional que Barraza encuentra entre los objetos inanimados ha de implicar una interpretación cautelosa de los resultados.

Los resultados de este capítulo, por tanto, son bastante coherentes con los obtenidos en el análisis sincrónico del capítulo anterior. En ambos casos ha quedado confirmado un efecto claro por parte de la afectación del objeto y, asimismo, un leve efecto de la telicidad sobre el marcado preposicional, que parece apuntar en la dirección opuesta a la esperada. Esta pequeña influencia en el MDO por parte de la telicidad se observó en el capítulo anterior y ahora a vuelto a hacerse patente en los siglos XIV y XVI, aunque carente de significatividad estadística en este caso. Por lo tanto, aunque es necesario ser cautos a la hora de excluir de forma completa la telicidad del conjunto de factores que determinan el MDO, en el análisis de los resultados de este capítulo se ha explicado que el leve efecto observado para la telicidad podría explicarse incluso atendiendo al distinto tipo de afectación que implican unos y otros verbos y, por lo tanto, es difícil mantener la teoría de que la telicidad desempeña un papel relevante para el explicar el MDO.

\subsection{Conclusiones}

Los resultados obtenidos del análisis de corpus presentado a lo largo de este capítulo conducen a replantearse el impacto de la telicidad sobre el MDO que había sido defendido anteriormente y a matizar el modo en que la afectación influye en el fenómeno. Por un lado, la telicidad no ha demostrado ejercer ningún tipo de impacto relevante sobre el uso del MDO en ninguno de los períodos estudiados; por el otro, la afectación sí ha manifestado un efecto significativo, pero solo sobre los objetos directos indefinidos.

En lo que a telicidad se refiere, una revisión de la bibliografía y los resultados obtenidos parecen indicar que las propuestas de su influencia en el marcado preposicional del objeto parten de la confusión de la telicidad con otros factores que suelen aparecen asociados. Así pues, los verbos que cita Torrego (1999) como ejemplos de verbos télicos que requieren MDO son insultar, curar, emborrachar y sobornar, es decir, que la justificación de que dichos verbos aparezcan con la 
marca preposicional en casi la totalidad de los casos ha de ser debida a la acción de otros factores como la afectación del objeto o, incluso, la elevada probabilidad de que seleccionen objetos directos humanos (véase von Heusinger 2008 para un análisis más detallado).

Respecto al impacto de la afectación cabe resumir que se produce a partir de la interacción con el factor de la definitud, pues tan solo ha sido posible comprobarlo en los objetos directos indefinidos. No se trata por tanto de un efecto de implicación directa entre objetos afectados y MDO, como se había defendido previamente.

Por lo tanto, ya han quedado respondidas tres de las cuatro preguntas que constituyen el punto de partida de esta investigación: las dos referidas a si la telicidad y la afectación ejercen un impacto sobre el MDO y la que se planteaba acerca de si era posible documentar dicho impacto en etapas previas del español.

En el capítulo 6, el objetivo es responder a la pregunta de cómo se explica que la afectación (que es el único factor que ha resultado relevante) actúe sobre el MDO de forma conjunta con otros factores como la animacidad o la definitud; es decir, se explora la relación que subyace al conjunto de factores que determinan el marcado preposicional y, por tanto, la motivación del propio fenómeno. El resultado pasa por plantear un modelo, en términos de prominencia, que pretende ofrecer una explicación holística y dinámica ante el fenómeno del MDO. 